\title{
ArcheoSciences
}

Revue d'archéométrie

33 (suppl.) | 2009

Mémoire du sol, espace des hommes

\section{Stepped frequency GPR survey with a multi- element array antenna: Results from field application on archaeological sites}

Neil Linford, Paul Linford, Louise Martin and Andy Payne

\section{OpenEdition}

Journals

Electronic version

URL: https://journals.openedition.org/archeosciences/1763

DOI: 10.4000/archeosciences. 1763

ISBN: 978-2-7535-1599-4

ISSN: $2104-3728$

Publisher

Presses universitaires de Rennes

Printed version

Date of publication: 30 October 2009

Number of pages: 317-319

ISBN: 978-2-7535-0943-6

ISSN: $1960-1360$

Electronic reference

Neil Linford, Paul Linford, Louise Martin and Andy Payne, "Stepped frequency GPR survey with a multielement array antenna: Results from field application on archaeological sites", ArcheoSciences [Online], 33 (suppl.) | 2009, Online since 30 October 2011, connection on 21 September 2021. URL: http:// journals.openedition.org/archeosciences/1763 ; DOI: https://doi.org/10.4000/archeosciences.1763 


\title{
Stepped frequency GPR survey with a multi-element array antenna: Results from field application on archaeological sites
}

\author{
Neil Linford*, Paul Linford*, \\ Louise Martin* and Andy Payne*
}

Key words: GPR, Stepped-frequency, Antenna array, Comparison to impulse data.

The value of large scale GPR surveys to landscape archaeology is becoming increasingly important (e.g. Nishimura and Goodman, 2000; Neubauer et al., 2002; Leckebusch, 2003; Linford, 2004). However, the use of conventional single channel instrumentation requires either a significant investment of time for data acquisition or a compromise between sampling methodology and the area of coverage. The recent development of multi-channel, vehicle towed GPR arrays offers the potential to obtain very detailed data sets across a wide frequency bandwidth that combines the full resolution of near-surface targets together with the investigation of a site to a significant depth of penetration.

This paper reports results from the field application of one such system: the $3 \mathrm{~d}$-radar, GeoScope using a range of multi-element array antennas with a cross line spacing between $0.055 \mathrm{~m}$ (B1831) and 0.075m (B1823C, B2431). The GeoScope is a stepped-frequency radar system covering a bandwidth from $100 \mathrm{MHz}$ to $2 \mathrm{GHz}$, recording from a maximum of 63 separate channels depending upon the interchangeable array antenna used (e.g. Binningsbø et al., 2000). The use of an interspersed pattern of different sized elements across the in-line array should, in theory, allow the spatial sampling requirements approaching the Nyquist

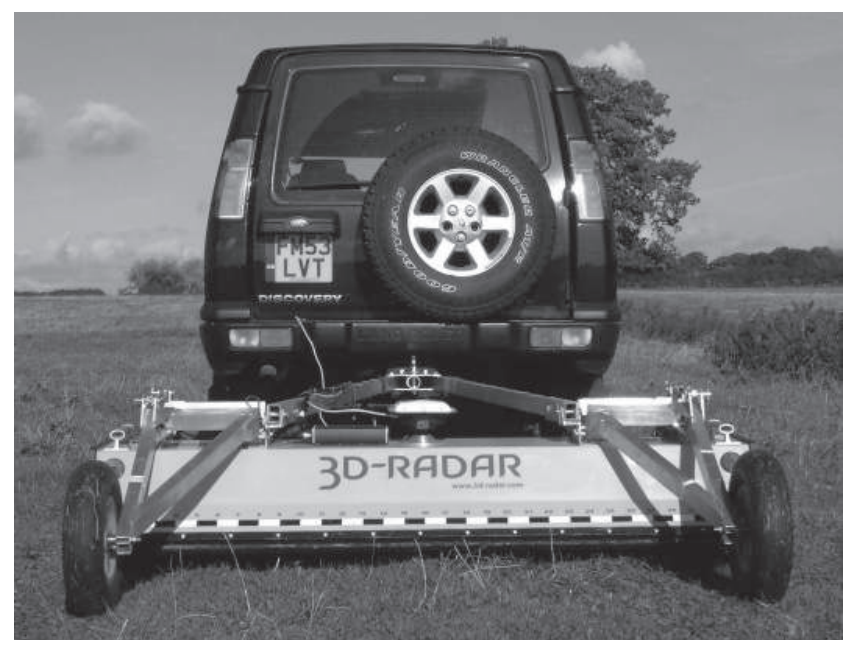

Figure 1: GeoScope B1831 air-launched antenna array mounted on a vehicle towed trailer for field survey. The precise location of the antenna is determined from a RTK GPS receiver mounted at the centre of the array.

limit to be met together with larger sized elements capable of recording reflections from a greater depth. The system also makes use of an air-launched antenna, potentially providing

\footnotetext{
* Geophysics Team, English Heritage. (neil.linford@english-heritage.org.uk)
} 
(A) PulseEkko $1000,450 \mathrm{MHz}$ antenna, $0.05 \mathrm{~m}$ inline spacing, 4 fold stack

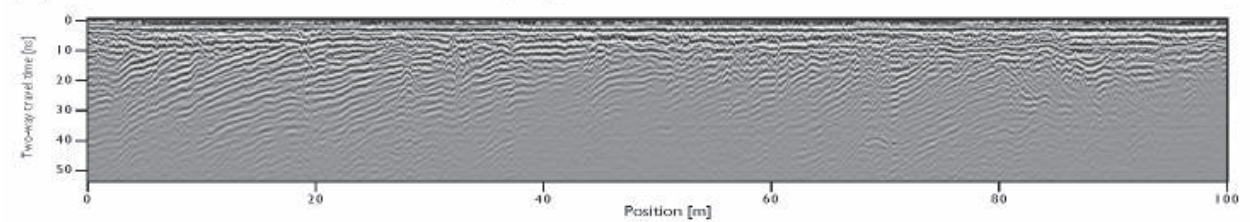

(B) Geoscope $0.05 \mathrm{~m}$ inline spacing, $100-1200 \mathrm{MHz}, 2 \mathrm{MHz}$ step, $10 \mu \mathrm{s}$ dwell time B1831 MEDIUM

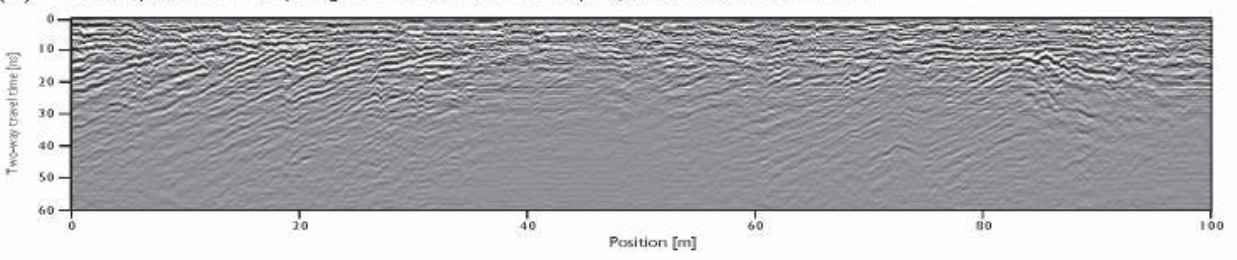

(C) PulseEkko $1000,450 \mathrm{MHz}$ antenna, $0.05 \mathrm{~m}$ inline spacing. 4 fold stack

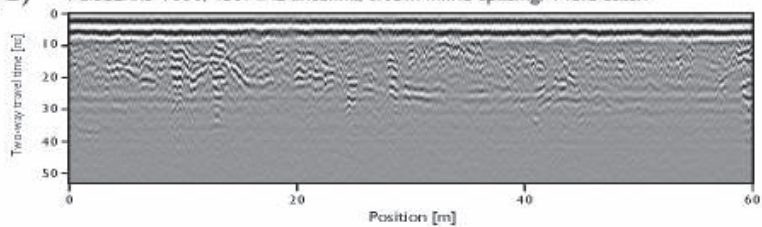

(D)

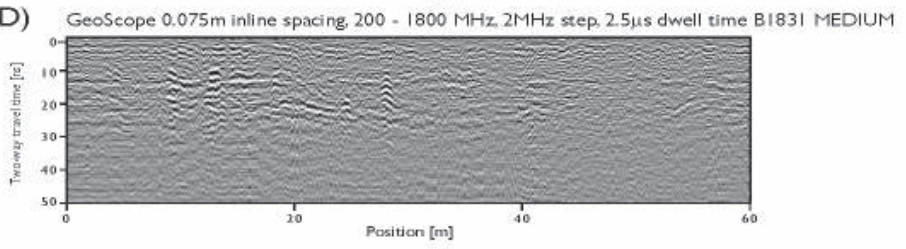

Figure 2: Comparative data profiles showing the variation of response with site conditions. At the first site an excellent correlation is found between (A) an impulse GPR with a ground-coupled antenna and (B) the GeoScope stepped-frequency system with an air-launched antenna array. Over sites with a higher degree of signal attenuation in the topsoil $(\mathrm{C})$ the ground-coupled impulse antenna demonstrates an improved signal to noise ratio compared to (D) the air-coupled array. Some variation between the two stepped-frequency data sets would be expected due to the differing inline sample interval, frequency range and dwell time, although these parameters were optimised for the field conditions at each site. a flexible range of vehicle mounting and transport options in the field. This could be of particular value over uneven terrain where maintaining good contact across a physically wide array may be more challenging with a ground-coupled antenna.

Field tests have been conducted with the GeoScope system over a number of sites where comparative data from other geophysical techniques, including survey with an impulse GPR, was also available. Initial results indicate a greater degree of dependence on site conditions compared to that exhibited by ground-coupled antenna, and some variation between the relative contribution from individual antenna elements. Whilst the more rapid signal attenuation recorded over certain sites is a concern, the very high sample density recorded by the array has revealed increased levels of detail within some significant archaeological structures. In addition, the size and complexity of the data processing required should not be underestimated: a single $1.8 \mathrm{~m}$ wide swath of data from a 31 channel array along a $100 \mathrm{~m}$ transect will produce a $-250 \mathrm{MB}$ raw data file, and processing to remove artefacts due to the air-launched antenna must be carefully applied to avoid any detrimental influence on more significant anomalies.
These preliminary results suggest modification of the antenna design and field methodology can be made to improve the use of the system for archaeological surveys. For example, using the full bandwidth and a long dwell time at each frequency step the speed of accurate data acquisition from a 31 channel array is approximately 0.6 ha per day and this, perhaps, limits the application to very large area surveys. However, selective use of the most productive subelements in the array would increase the rate of coverage for a more rapid survey at a reduced sample interval, and allow data quality to be improved through the use of a limited bandwidth to match the particular size of the sub-elements. Subsequent high resolution survey could then target the areas containing the most significant anomalies. In addition, these results suggest that a ground-coupled antenna array may well be required to allow the system to achieve its full potential for archaeological surveys. 


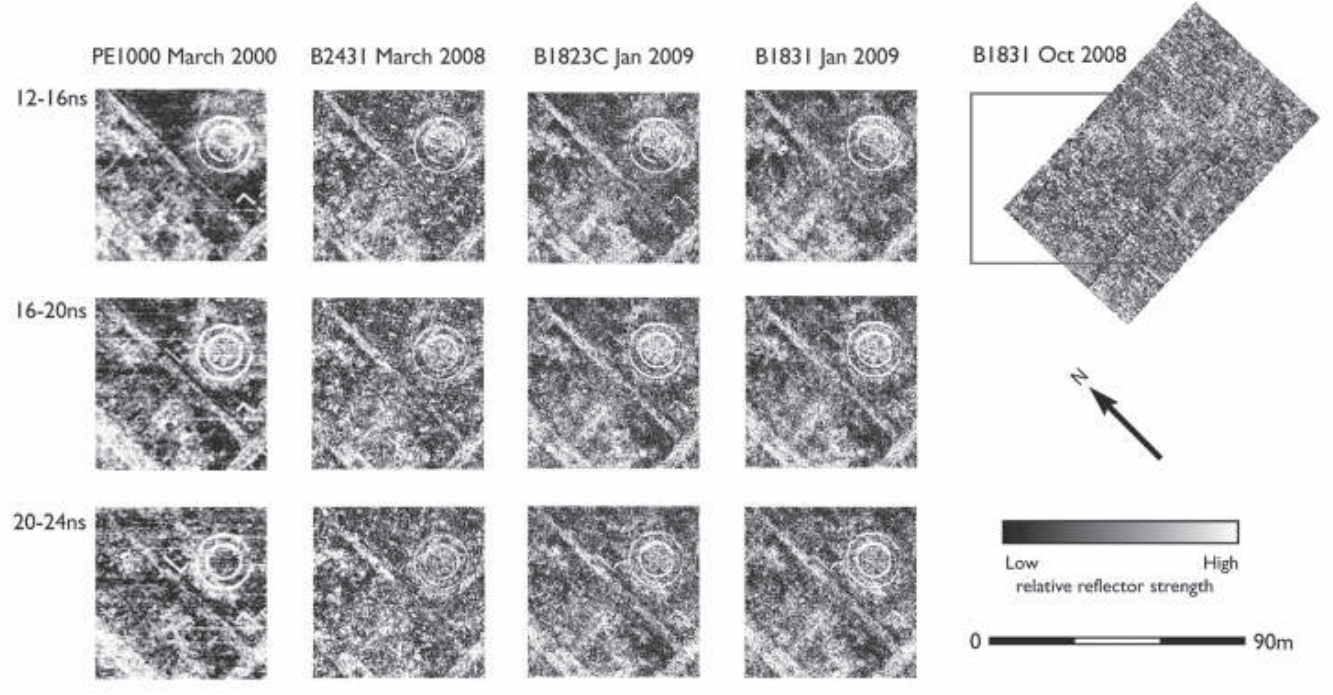

Figure 3: Selective amplitude time slices collected over a Romano-Celtic temple at Silchester, Hants., showing a comparison between the original impulse GPR survey, conducted in March 2000 with a single channel $450 \mathrm{MHz}$ centre frequency antenna (PE1000), and subsequent field tests of the GeoScope system with three air-launched antenna arrays (B2431, B1823C and B1831). The high sample density of the GeoScope data reveals additional structural elements of the circular temple, but some more subtle anomalies appear to be better resolved in the impulse data. This may well be due to the additional processing required to remove artefacts from the air-launched antenna array data or differing site conditions. It is unclear whether the very poor results recorded with the GeoScope in October 2008 were due to operator error, instrument failure or the particular field conditions at the time of the survey.

\section{References}

Binningsbø, J., Eide, E. and HJelmstad, J., 2000. $3 D$ migration of GPR array antenna data. In, GPR 2000: Eighth International Conference on Ground Penetrating Radar 2000, Gold Coast, Australia.

Lecкebusch, J., 2003. Ground-Penetrating Radar: A modern three-dimensional prospection method. Archaeological Prospection, 10 (4): 213-41.
Linford, N., 2004. From Hypocaust to Hyperbola: Ground Penetrating Radar surveys over mainly Roman remains in the U.K. Archaeological Prospection 11 (4): 237-246.

Neubauer, W., Eder-Hinterleitner, A., Seren, S. and Melichar, P., 2002. Georadar in the Roman Civil Town Carnuntum, Austria: An approach for archaeological interpretation of GPR data. Archaeological Prospection, 9: 135-56.

Nishimura, Y. and Goodman, D., 2000. Ground-Penetrating Radar survey at Wroxeter. Archaeological Prospection, 2: 101-6. 